\title{
电子自旋共振波谱及苂光偏振技术研究 山莨茇碱对磷脂脂质体流动性的影响
}

\author{
黄 芬 陈建文 傅一工 吴玉薇 \\ (中国科学院生物物理研究所,北京) \\ 王者福张增佑 \\ (南开大学元素有机化学研究所, 天津)
}

前文 ${ }^{[1]}$ 报道了用差示扫描量热法 (DSC) 技术研究山莨宕碱、东莨若碱、樟柳碱以及阿托 品对二棕相酰磷脂酰胆碱 (DPPC) 脂质体流动性的影响,结果表明,山茛宕碱与阿托品较明显 地增加脂质体的流动性. 本文进一步采用电子自旋共振波谱 (ESR), 荧光偏振以及冰冻断 裂电子显微镜技术, 同样证明山荐宕碱能增加 DPPC 脂质体的流动性.

\section{一、材料 和方法}

DPPC, 1,6-二苯基已三烯（DPH）均系美国 Sigma 公司产品, DPPC 经薄层层析鉴定为 单一成分. 山茛菅碱氢澳酸盐系成都第一制药厂生产. $2,2,6,6$-四甲基哌啶氮氧自由基探 针 (TEMPO) 系中国科学院生物物理研究所䜣文娟同志赠与. N-2-羟乙基哌嗪-N-2-乙磺酸 (HEPES) 为瑞士 Fluka 产品.

1. 磷脂脂质体制备 详细操作参照前文 ${ }^{[1]}$.

用国产 YKH-1 型液体快速混合器代替超声法可制备大的脂质体，作为冰冻断裂电子显 微镜的样品. DPPC 最终浓度为 40 毫克/ 毫升.

2. 电子自旋共振波谱技术 取一定量 DPPC 脂质体悬液 (120 毫克/言升) 加人自旋标 记探针 TEMPO 溶液, 使 TEMPO 在脂质体中最终浓度为 $5 \times 10^{-4} M$, 将样品装入 1 毫米内 径石英毛细管中, 在 JES-3BX 顺磁共振波谱仪微波腔中测试. 温度变化范围 $20-60^{\circ} \mathrm{C}$, 温 差 $\pm 1{ }^{\circ} \mathrm{C}$.

3. 苂光偏振技术 $2 \times 10^{-3} M \mathrm{DPH}$ 的四氯呋喃溶液, 使用前用磷酸缓冲液生理盐水 （PBS）缓冲液 $(0.01 M, \mathrm{pH} 7.4)$ 稀释 1000 倍, DPPC 脂质体与 DPH 溶液等体积混合,DPPC 最终浓度为 0.5 毫克/毫升, 样品在 $30^{\circ} \mathrm{C}$ 保温 30 分钟, 然后在室温放置 1.5 小时, 用 Hitachi MPF-4 型苂光分光光度计进行测量. 激发光波长 $360 \mathrm{~nm}$, 发射光波长 $430 \mathrm{~nm}$, 苂光偏振度 $P=\left(I_{\| \mid}-G I_{\perp}\right) /\left(I_{\| \mid}+G I_{\perp}\right), I_{\mid l}$ 及 $I_{\perp}$ 分别表示通过平行及垂直于激发光的偏振方向的 偏 振器所观察到的苂光强度, 其中 $\mathrm{G}$ 为校正因子. 微粘度 $(\eta)$ 根据 Perrin 公式计算 ${ }^{[2]}$, 苂光偏振 度 $(P)$ 值与微粘度 $(\eta)$ 值, 反映膜脂流动性的变化: $P$ 值越小, $\eta$ 值越小, 膜脂的流动性越大.

4. 冰冻断裂电子显微镜技术 取一定体积 DPPC 脂质体悬液或含山薮宕碱的脂质体,

本文 1983 年 12 月 3 日收到.

第 17 期 
加人甘油后进行冰冻断裂。详细操作参照前文 ${ }^{[3]}$.

\section{二、结果和讨论}

1. ESR 根据 Shimshick 与 McConnell ${ }^{43}$ 的方法, 用测量 TEMPO 在高场共振时出现 的超精细分裂谱线 $H$ 与 $P$ 的高度来计算谱参数 $(f)$, 图 1 中 $H$ 的高度代表 TEMPO 渗人 DPPC 脂质体疏水相的量, $P$ 代表 TEMPO 在水相的量. $f=\frac{H}{H+P}, f$ 对温度作图, 就可求出 DPPC 脂质体的相变温度. 图 2 为含有不同浓度山莨若碱 DPPC 脂质体的相变曲线. 从图 中可见，当 DPPC 脂质体含 30 克分子 \% 50 克分子 \%山莨菪碱时，其相变温度分别降 低 $2^{\circ} \mathrm{C}$ 与 $4^{\circ} \mathrm{C}$ 左右, 表明随山莨若碱浓度的增加, 明显地降低 DPPC 脂质体相变温度, 增加膜的 流动性. 结果与 DSC 完全一致.

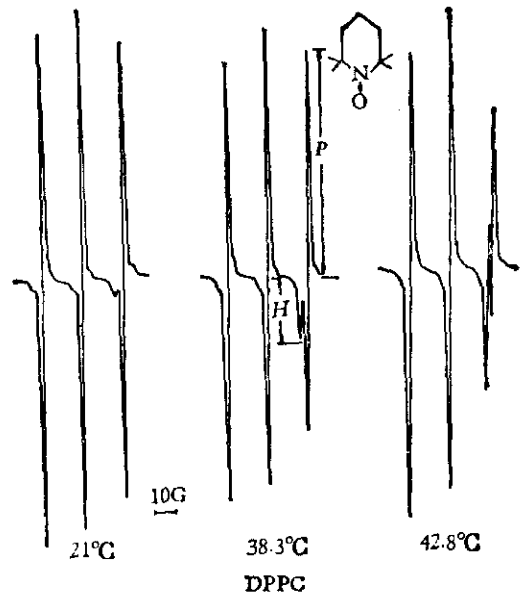

图 1 TEMPO 渗人 DPC 脂质体后 在不同温度时的 ESR 波谱

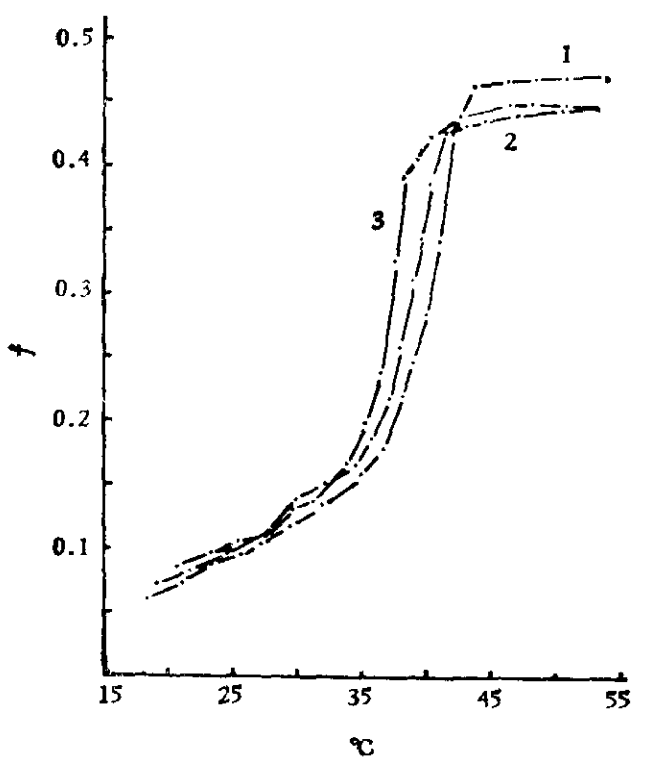

图 2 DPPC 脂质体及含有不同浓度山莨蓉碱 的 DPPC 脂质体的相变曲线

1. DPPC 脂质体；2.含有 30 克分子\%山莨蔩碱 的 DPPC 脂质体；3. 含有 50 克分子\%山莨桼碱 的 DPPC 脂质体

2. 苂光偏振 表 1 为山莨荢碱对 DPPC 脂质体苂光偏振度 $(P)$ 及微粘度 $(\eta)$ 的影响. 在 $25^{\circ} \mathrm{C}$ 时含有 50 克分子 $\%$ 山莨荢碱的 DPPC 脂质体，其 $P$ 值与对照比较变化不大，若温度 上升至 DPPC 相变温度 $\left(41^{\circ} \mathrm{C}\right)$ 时, 则 $P$ 值比对照低, 微粘度也降低, 说明膜脂的流动性增加. DPPC 脂质体在其相变温度附近苂光偏振度急剧下降,与 Andrich 等 ${ }^{[5]}$ 的报道相似.

表 1 山莨若碱对 DPPC 脂质体荧光偏振度 $(P)$ 以及微粘度 $(\eta)$ 的影响



数据经 $\mathrm{t}$ 检器, 标准离差统计处理, 实验次数 8 次以上. a. $p<0.001 ; \mathrm{b} . p<0.001$. 
3. 冰冻断裂电子显微镜技术当 DPPC 脂质体含有 30 克分子\%山莨若碱时, 与对照 比较 DPPC 的晶相结构发生明显扰乱(图 3a、b) DPPC 脂质体冰冻断裂面周期性带状条纹消 失,出现无序结构,说明山莨宕碱促使 DPPC 脂质体从晶相结构向液晶相过渡.

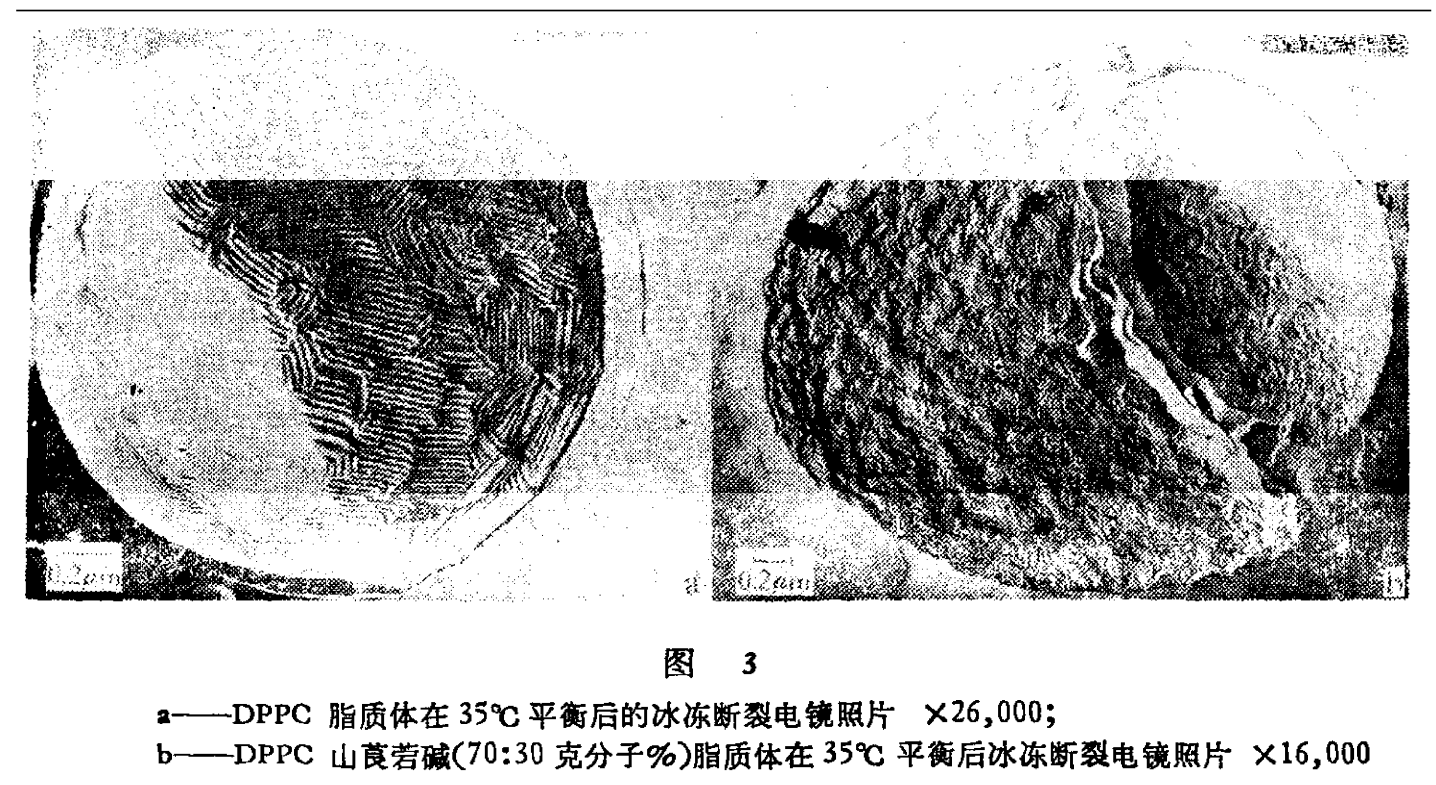

近年来,不少实验结果表明,大部分麻醉药均可增加膜脂的流动性. Hubbel 和 McConneli ${ }^{[6]}$ 采用 TEMPO 自旋标记探针研究生物膜, 结果发现局部麻醉药可使膜的流动性增加, Galla ${ }^{[7]}$ 等用 TEMPO 渗入含有多粘菌素的二棕㭣酰磷脂酸（DPPA）脂质体研究其在高压作用下的 膜的性质. 我们曾用 DSC 进行研究, 结果表明, 山莨宕碱浓度为 10 克分子\%, DPPC 脂质体 “预融峰”消失, 当山莨若碱与 DPPC 以等克分子比例混合时, 脂质体相变温度下降 $2^{\circ} \mathrm{C}$ 左右. 山莨宕碱主要作用于 DPPC 脂质体极性头部, 从而影响脂双层疏水区，因此反映出膜脂的流 动性增加幅度不大. 由于一种实验手段有其局限性, 我们又采用了 ESR 等不同的方法, 进 一步证实了山莨宕碱对 DPPC 脂质体流动性的影响. 最近我们发现山莨宕碱对酸性磷脂作 用比中性磷脂 DPPC 更为显著,并出现分相现象 ${ }^{[8]}$. 研究工作正在进行中.

\section{参考献}

[1] 王苏民等,科学通报, 28(1983)，1:60-62.

[ 2 ] Shinitzky, M. and Barenholz, Y. J., J. Biol. Chemt, 249(1974), 2652--2657.

[ 3 ] 黄芬等,科学通报, 27(1982), 5:305-307.

[ 4 ] Shimshick, E. and McConnell, H. M., Biochemistry, 12(1973), 2351-2360.

[ 5 ] Andrich, M. P. and Vanderkooi, J. M., Biachemistry, 13(1976), 1257-1261.

[ 6 ] Hubbel, W. L. and McConnell, H. M., Proc. Natl. Acad. Sci. U. S. A., 61(1968), 12-16.

[ 7 ] Galla, H. J. and Trudell, J. R., Biochim. Biophys. Acta, 602 (1980), 522-530.

[8] 王苏民等,科学通报, 28(1983)，14：878-880. 